\title{
Reading process as first stage of the publication industry: Have Tunisian novice researchers acquired the appropriate reading skills to do a good literature review
}

\author{
Chokri Smaoui $^{1}$, Elhoucine Essefi ${ }^{2}$ \\ ${ }^{1}$ RU: DISCOURSE ANALYSIS. Faculty of Letters and Humanities of Sfax, Sfax, Tunisia \\ ${ }^{2}$ National Engineering School of Sfax, Road of Soukra, km 4 Zipcode3038, Sfax, Tunisia
}

Email address:

hocinsefi@yahoo.fr(E. Essefi)

\section{To cite this article:}

Chokri Smaoui, Elhoucine Essefi. Reading Process as First Stage of the Publication Industry: Have Tunisian Novice Researchers Acquired the Appropriate Reading Skills to do a Good Literature Review. International Journal of Language and Linguistics.

Vol. 3, No. 1, 2015, pp. 22-26. doi: 10.11648/j.ij11.20150301.14

\begin{abstract}
This works predicted, by studying the deep rooted reasons behind difficulties of Tunisian novice researchers with efficient reading of the scientific genre, that difficulties are rooted in their educational system. It simulates the line of thinking of the strong version of the Contrastive Analysis Hypothesis (CAH). The common point between the method of this work and the strong version of the $\mathrm{CAH}$ lies in using a predictive approach. By confusing its social and scientific status, this system neglected the importance of English in scientific communication. Furthermore, the weak programs and unskilled teachers in terms of scientific genre deepened these difficulties. Consequently, this study based on Contrastive Linguistics foresaw that Tunisian novice researchers are more than likely to fail doing the first and vital stage of the publication industry: the literature review.
\end{abstract}

Keywords: Publication Industry, Language Acquisition (LA), Contrastive Linguistics, Scientific Discourse, Scientific Status, Contrastive Analysis Hypothesis (CAH), Scientific Genre, Educational System, Social Status

\section{Introduction}

The scientific quality of any paper or Thesis is influenced not only by the quality and the novelty of its literature review, but also by the capacity of its author to benefit from the literature. As for the Tunisian context, in the face of the huge and rich Anglophone literature, Tunisian novice researchers must use the appropriate reading skills to profit from its content. But, recently, Dhieb-Henia (2003) noticed that Tunisian learners face many difficulties to appropriately read scientific texts in English. Accordingly, the focus in this paper is meant to be on the difficulties of going through the first linguistic stage of the publication industry: the literature review. In the same vein, this work will predict the deep rooted reasons behind these difficulties with the scientific genre by pinpointing the gap between their acquisition of English in the Tunisian context and the required skills for a good literature review.

\section{Method}

As far as the methodology adopted is concerned, this work adopts the approach of the school of Contrastive Linguistics (Stockwell and Martin, 1965). It simulates the line of thinking of the strong version of the Contrastive Analysis Hypothesis $(\mathrm{CAH})$. The common point between the method of this work and the strong version of the $\mathrm{CAH}$ lies in using a predictive approach. On the one hand, the strong version of the $\mathrm{CAH}$ predicts the difficulties that second language learners face due to the phenomenon of interference of language one in language two. It suggests that the bigger the difference between language one and language two is, the greater difficulties of successfully learning language two are (see Wardaugh 1970 for a criticism of this strong version). On the other hand, this work predicts the difficulties of Tunisian novice researchers with efficiently reading the scientific genre by comparing the acquisition of English of Tunisian novice researchers during their education and the reading skills required to comprehend the scientific genre. The bigger the difference between the required and the acquired, the greater the difficulties are. These difficulties of reading the scientific product may be also classified according to the weak version as receptive errors (Corder, 1974). Such errors per se do not represent a great danger. But 
they will be the foreground of the errors made in the written product. For instance, by making a receptive error, the author may understand and write, in his paper or Thesis, an idea deviating from or even totally contradicting an original idea of another author.

\section{Results}

To clearly understand difficulties of Tunisian novice researchers with reading the scientific genre, this study will shed light on the contrast between the acquired skills in the Tunisian context and required skills discussed in the literature. In doing so, it may pinpoint who is to blame for this deficiency. This acquired/required contrast is actually a contrast between the acquisition of English in the Tunisian context and the appropriate reading skills for a good literature review generally used by native speakers or proficient L2 speakers.

\subsection{Acquisition of English in the Tunisian Context}

Most studies have dealt with the reading strategies of native and English Second Language (ESL) readers (e.g., Bazerman, 1985). As one of the few researchers interested in the Tunisian context, Dhieb-Henia (2003) examined the reading practices of post-graduate university Tunisian students who are considered in her study as English Foreign Language (EFL) speakers, since they were studying in a nonEnglish speaking country belonging to the francophone camp. Nevertheless, in Tunisia, the situation of English is exceptional due to its status and teaching methodology. This study will re-discuss the status of English in Tunisia, the teaching methodology and their effect on reading skills.

\subsubsection{Status of English in the Tunisian Context}

Three languages compete in the Tunisian scene: Arabic, French and English. As for the status of English, DhiebHenia (2003) considered English as a foreign or third language after Arabic and French. But in this study, we will make a distinction between social status and scientific status. On the one hand, the social status is related to languages used in communication between citizens of the country in daily life communication, administrative traffics and official TV programs. In this regards, Arabic (Tunisian dialect and standard Arabic) is protected by the government for political, cultural and religious purposes as the first social language; French is maintained for historical and economic purposes as the second social language; and English is now rising slightly as the third social language due to media and waves of globalization. These social statuses remain stable during short and mid terms (Tab: 1); their change needs a radical change in the Tunisian society or an abrupt change in the political aims. On the other hand, the scientific status is related to languages used in schools. This use may be by teaching the language itself or by teaching other courses in this language. Actually, as it shown in Tab: 1, the statuses of the three languages in Tunisia witness radical changes during the educational career of Tunisian novice researchers; it is worth noting that this table should be proved by deep analysis of the statistical data from the Tunisian context. Taking English as an example, its appearance in the scientific scene as a second language is only from the university studies at the age of about 20 years. Here the problem is twofold. First, English is internationally the first language of science, and not the second as it is considered in Tunisia. Second, acquisition of a language in adulthood is until now controversially discussed among scholars (see, e.g., Singleton 2003). These shifts may also forbid Tunisian novice researchers from building a continuum of scientific register in one language; since they study courses in Arabic during the primary and basic schools; then, they study courses in French during secondary and university studies; and eventually they find themselves abruptly in face of English communities during their research careers. This abrupt contact with English is due to negligence in the Tunisian educational system that only encourages learners to get bits and pieces from different languages without good mastery of any language. Accordingly, Tunisian novice researchers find themselves at a loss due to the overlap of different vocabularies. In this case, interference is more than likely to occur.

Table 1. Distinction between social status and scientific status of Arabic, French and English during the educational career of Tunisian novice researchers.

\begin{tabular}{|c|c|c|c|c|c|c|c|}
\hline \multirow{2}{*}{ Age (years) } & \multirow{2}{*}{ Educational stage } & \multicolumn{2}{|l|}{ Arabic } & \multicolumn{2}{|l|}{ French } & \multicolumn{2}{|l|}{ English } \\
\hline & & Scientific status & Social status & Scientific status & Social status & Scientific status & Social status \\
\hline$<6$ & Nursery school & First & First & Not defined & Not defined & Not defined & Not defined \\
\hline $6-9$ & Primary school & First & First & Not defined & Not defined & Not defined & Not defined \\
\hline $9-12$ & Primary school & First & First & Not defined & Second & Not defined & Not defined \\
\hline $12-15$ & Basic school & First & First & Not defined & Second & Not defined & Third \\
\hline $15-19$ & Secondary school & Second & First & First & Second & Not defined & Third \\
\hline $19-23$ & University studies & Not defined & First & First & Second & Second & Third \\
\hline
\end{tabular}

By entering in research activities, Tunisian novice researchers recognize the loss of French and Arabic of their weights. At this stage, they feel the gap between the actual international status of English as the first language of science and the status of English in Tunisia as the second language of science. Eventually, they are externally and internally motivated to learn English; but, unfortunately, it will be too late to realise an abrupt increase in their levels. Their levels in English may be slightly improved but with considerable loss in time and money.

\subsubsection{Programs and Teaching Methodology}

Learning English for Tunisian students starts at to the secondary level and continues until the university level. 
Recently, the Tunisian government attempted to introduce the teaching of English for the new generations from the primary levels; but these generations are not yet at the research stage. Thus, the beginning of English acquisition will be considered in this study from the secondary level. The number of the instructed hours decreases from the secondary school (two to four hours per week) to the tertiary level science institutions (one and a half to three hours per week). Concerning the content and teaching methodology, at the secondary school level, the great bulk of English teaching is meant to develop a general proficiency in the language. At the tertiary level, an as yet open debate is still whether to focus on general proficiency in English or to target more specific objectives based on the learners' needs. During the educational career of Tunisian novice researchers, one can notice that the acquisition of this third language is neglected due to the special care given to Arabic and French. During the basic education levels, the content of courses is taught in Arabic. The scientific status of English as a third language that coincides with its social status as a third language makes it neglected in terms of scientific register. During the secondary levels, the negligence of English in Tunisia is due to three factors. First, the numbers of the instructed hours and coefficients of English (see Tunisian official programs) are not enough to impose an extrinsic type of motivation. Second, generally speaking, the Tunisian students at this stage will not have completely mastered French and Arabic. Furthermore, the content of their courses (taught in French and Arabic) is too overloaded. Their minds are crowded and otherwise engaged in learning French, Arabic and courses of other specialities. Thus, their abilities to learn a third language are generally weak. Third, Tunisian citizens have limited knowledge about the Anglophone cultures; the few data about the Anglophone cultures are given by the Arabic media according to their agenda; these media spread a negative impression in the framework of the PalestinianIsraeli conflict. Hence, being influenced by their social environment, Tunisian students are more likely to have a negative attitude; they are not intrinsically motivated to learn English. At university levels, Arabic eclipses and the focus of students is on details of their specialities taught in French. English jumps to occupy a new status as the second language of science. Following the advice of their instructors at university, Tunisian students feel an intrinsic motivation to learn English. But, as many students declare, the content and the methodology do not reach their expectations. Actually, this point is confirmed when investigating opinions of many Tunisian researchers in the laboratory (3E). According to their claims, many researchers feel the gap between the type of English given in the secondary and graduate levels and that needed for academic and professional success at postgraduate level and beyond. As for critics of this teaching methodology, recently, Dhieb-Henia (2003) found out that general proficiency in the language is not enough for reading English literature and compiling a scientific discourse to an English speaking community.

As a result of the deficiencies of Tunisian programs in terms of content and methodology, in Tunisian institutions, where reading and publishing Research Articles become urgent requirements, students spend long years trying to gain understanding of the scientific genre and they may fail in this endeavour; because their knowledge of Research Articles reading has not been adequately developed due to the gap between the content and teaching methodology of the official programs and requirements of reading the scientific discourse.

\subsection{Gap between the Required Reading Skills for a Good Literature Review and the Tunisian Context}

By recognizing the gap between reading skills required to do a good literature review and competences of Tunisian novice researchers, one can understand their suffering with the scientific genre. Actually, a better reading proficiency may be achieved by following reading strategies of English for Specific Purposes, using these strategies metacognitively and following the right method of evaluation to notice the degree of progression.

\subsubsection{Reading Strategies of English for Specific Purpose (ESP)}

Studies examining the reading strategies of good and poor readers have shown a differential use of strategies pertaining to text type. A good reader should by rights use different reading strategies according to the different text types. Golinkoff (1975) went so far to say that one of the main characteristics of a poor reader is reading all types of texts in the same manner. In the context of Second Language Acquisition, Jiménez et al. (1996) show that less successful bilingual readers manipulate similarly narrative and expository texts. In order to pinpoint the deficiency of Tunisian novice researchers in terms of reading skills, one must compare in this study their case with a reference case of native speakers.

On the one hand, Bazerman (1985), through interviewing and observing native speakers, collected data on the reading processes of seven native speaker physicists with the aim of understanding how they tackled the literature in their field. Since they were L1 readers, these native speakers had a certain level of proficiency in the language, and had some experience in reading the literature; accordingly, their reading habits and strategies may be considered as typical. Although the focus was on reading purposes and background knowledge, and how they affected comprehension of the materials, Bazerman (1985) shed light on the type of strategies these readers used. The results of the interviews and observations showed that, based on the specific needs of their research projects, these professionals made purposeful choices as to what to read. For example, they scanned the tables of content of selected journals in their field. Also, they read selectively and kept alert for key words, and when such words were identified, the subjects would adopt a more careful reading process. These scientists varied their reading not only according to the type of information presented, but also depending on what they wanted to do with it. Firstly, they skim through the article to form an overall impression of 
it. Subsequently, they scan more carefully selected equations and formulae, and verify them. They might even go for a third, more careful and detailed reading if their purpose was to integrate findings within their own work. With these purposes in mind, they sometimes ignore points, with which they disagreed, and selected only those which were novel and which might be assimilated into their own on-going work.

On the other hand, in the Tunisian context, Daoud (1991) pinpointed the difficulties faced by Arabic and French native speakers when reading English Scientific Texts (EST) in their area. They are unable to recognise the nature of English Scientific Text discourse and to perceive the rhetorical organisation of English Scientific Text. Dhieb-Henia (2003), investigating the reading habits of a sample of Tunisian students in science, came up three general observations. First, little attention was paid to metatext (author's purpose, audience). Second, a lack of flexibility is noticed at both rhetorical and stylistic levels. Third, students displayed an incomplete, fragmented and sometimes inappropriate mental representation of the texts.

By discussing the underscored reading strategies debated in the international literature (Bazerman, 1985; Golinkoff, 1975; Jiménez et al., 1996) and works related to the Tunisian context (Daoud, 1991; Dhieb-Henia, 2003), one can predict that Tunisian novice researchers would face reading difficulties associated with lacunae in official programs.

\subsubsection{Metacognitive Strategies to Ameliorate Reading Processes}

Reading strategies are conscious and flexible plans that readers apply to particular texts and tasks (Pearson and Fielding, 1991). These strategies admit that learning and reading a language are teachable skills (Vygotsky, 1962). The explicit teaching of specific strategies for improving students' reading comprehension has received specific interest. For instance, certain studies in L1 and L2 contexts (e.g., Jimenez et al. 1996) showed that potentially useful strategies for effective reading were attributed to the level of the metacognitive awareness of the students; because many poor readers did not lack cognitive strategies but failed to access them metacognitively (Carrell, 1998). These studies, most of which were carried out in L1 contexts, have indicated the beneficial effect of metacognitive strategy training and reported significant improvements in students' reading comprehension performance after receiving some metacognitive instruction. In this sense, the success of the reading process was not closely connected only to the strategies used, but also to keeping track of the task at hand, as well as to considering characteristics of the texts being read.

Actually, Dhieb-Henia (2003) discussed the use of metacognitive strategies in reading by Tunisian students; she proved that Tunisian students lack such strategies to efficiently tackle the reading process. With regard to this deficiency, it can be predicted that Tunisian novice researchers are more than likely to lack such strategies. These metacognitive strategies could by no means be separated from the concept of power previously discussed. Being aware of the relation of power between gatekeepers and authors, the reader is more likely to understand the persuasive style used in the scientific discourse.

\subsubsection{Evaluation of Reading Process Efficiency}

Recently, the evaluation of process of reading comprehension has witnessed a noticeable shift from product-oriented (e.g., tests) or observational techniques (e.g., surveys and tests) toward process-oriented techniques (e.g., Rankin, 1988). During the reading process, the introspective data generated could be classified into concurrent and retrospective verbal reports. Concurrent verbal reports, also referred to as simultaneous verbal reporting, or thinking aloud, could be defined as verbalizing what one is thinking of while attending to the task. As described by Someren et al. (1994), this technique "consists of asking people to think aloud while solving a problem and analysing the resulting verbal protocols." As for retrospective verbal reports, Cohen (1987) distinguishes between immediate (e.g., an hour from the event) and delayed (a few hours, days, or even weeks after the event) reports. The language used represents a methodological concern in the concurrent and retrospective verbal reports approach. In English as a Foreign language contexts, the partial mastery may affect the reading process. A certain number of studies focusing on the relationship between L2 comprehension and production demonstrated that the language used affected production (Chen and Donin, 1997; Donin and Silva, 1993). When reporting in their native language, people have recalled more and have demonstrated more use of higher-level processing (Donin and Silva, 1993) compared to reporting in their second or foreign language. Barnett (1989) contended that "students may not be able to show their comprehension of a text due to their inability to express themselves well in English (their foreign language) in their recall protocols". Thus, contrary to what is adopted by many teachers, students should use their native language to express their difficulties.

Unfortunately, in the Tunisian context, the traditional methods are still in use during the secondary and tertiary levels. In the mistaken belief that communicating only in English is the best way to improve students' levels, Tunisian Teachers usually forbid communication in Arabic or French within the classroom. In doing so, they lose the latest way of communication with their students; because many students do not have the minimum levels to express their needs concerning unclear points in their courses. The gap between students and their teacher increases with their progression in such a way they find themselves totally lost. Recently, Dhieb-Henia (2003) used retrospection to evaluate the efficiency of the metacognitive training on Tunisian researchers; she made them choose the language to communicate with. In doing so, these Tunisian students were able to pinpoint by themselves the deficiency of their old habits of reading a Research Article; their comments fully convergence with our comment concerning the deficiency of Tunisian official programs. 


\section{Conclusion and Pedagogical Implications}

The literature review is a vital stage in the publication industry; it provides researchers with results and methods of recent studies and saves the researchers the effort of going through previous works. As it is proven in previous works (e.g., Essefi, 2009), the Anglophone literature is very fertile; but it needs a good mastery of the reading process in English. By studying the gap between required skills of a successful reading process of the scientific text and the acquired skills in the Tunisian context, one can say that Tunisian novice researchers are far from having the basics to overcome their difficulties with reading in English. Because Tunisian novice researchers have not learned during their educational career the appropriate reading skills to face requirements of the comprehension of the scientific discourse, their difficulties are thus rooted in their educational system, which underestimates, in its first years, the status of English and caters only for 'weak' programs taught by unskilled teachers (Lowe, 1996; Dhieb-Henia, 2003). Consequently, this study foresees that Tunisian novice researchers are more than likely to fail doing the first and vital stage of the publication industry.

\section{References}

[1] Barnett, M. A. (1989). More than meets the eye: Foreign language reading theory and practice. Englewood Cliffs, NJ: Prentice Hall Regents.

[2] Bazerman, C. (1985). Physicist reading physics: schema-laden purposes and purpose-laden schema. Written Communication, $2,3-23$.

[3] Carrell, P. L. (1998). Can reading strategies be successfully taught? The Language Teacher (online), 22/3, 55 paragraphs. Available:

http://langue.hyper.chubu.ac.jp./jalt/pub/tlt/98/mar/carrell.html.

[4] Chen, Q., \& Donin, J. (1997). Discourse processing of first and second language biology texts: effects of language proficiency and domain-specific knowledge. The Modern Language Journal, 81, 209-227.

[5] Cohen, A. D. (1987). Using verbal reports in research on language learning. In C. Faerch, \& G. Kasper (Eds.), Introspection in second language research (pp. 82-95). Philadelphia: Multilingual Matters.

[6] Corder, S. (1974). 'Idiosyncratic Dialects and Error Analysis'. In Richards, J. (Ed.). Error analysis: Perspectives on Second Language Acquisition. 158-171. Essex: Longman.

[7] Daoud, M. (1991). The processing of EST discourse: Arabic and French speakers' recognition of rhetorical relationships in Engineering texts. Unpublished PhD thesis. Los Angeles: University of California.

[8] Dhieb-Henia, N. (2003). Evaluating the effectiveness of metacognitive strategy training for reading research articles in an ESP context. English for Specific Purposes, 22 (2003) 387417.

[9] Donin, J., \& Silva, M. (1993). The relationship between firstand second-language reading comprehension of occupationspecific texts. Language Learning, 43, 373-401.

[10] Golinkoff, R. M. (1975). A comparison of reading comprehension processes in good and poor comprehenders. Reading Research Quarterly, 11, 623-659.

[11] Jiménez, R. T., Garcia, G. E., \& Pearson, P. D. (1996). The reading strategies of bilingual Latina/o students who are successful English readers: opportunities and obstacles. Reading Research Quarterly, 31, 90-112.

[12] Pearson, P. D., \& Fielding, L. (1991). Comprehension instruction. In R. Barr et al. (Eds.), Handbook of reading research, Volume II (pp. 815-860). New York: Longman.

[13] Rankin, J. M. (1988). Designing thinking aloud strategies in ESL reading. Reading in a Foreign Language, 4(2), 119-132.

[14] Singleton, D. (2005). The critical period hypothesis : a coat of many colours. IRAL 43: 269-85.

[15] Someren, M, Barnard, Y. V, and Sandberg, J. (1994). The Think Aloud Method (London, The Academia Press).

[16] Stockwell, R.P., and Martin, J. W. (1965). The grammatical structure of English and Spanish. Chicago: University of Chicago Press.

[17] Vygotsky, L. S. (1962). Thought and Language. Cambridge, MA: MIT Press.

[18] Wardaugh, R. (1970). The contrastive analysis hypothesis. TESOL Quarterly 4: 123-30. 